\title{
Teaching methods for end-user searching: A checklist for planning
}

\author{
Prepared by the ACRL Bibliographic Instruction Section \\ Emerging Technologies in Instruction Committee
}

Use this guide for planning your instruction program.

1

he checklist presented below has been two or three years in the writing and publishing. It is instructive to all of us who think about, write about, and use information technology, that even in this very short amount of time, the online landscape has changed radically, as have the expectations and technological sophistication of our clients. The checklist originated with discussions in the ACRL Bibliographic Instruction Section Computer Concerns Committee (now the Emerging Technologies in Instruction Committee) regarding methods of teaching end-users to search online databases, such as BRS and DIALOG - a practice which was still fairly unique at the time, particularly outside of special libraries. David King, then chair of the committee, drafted a core document intended to provide those involved in planning end-user instruction programs with a list of issues, concerns, and options. This draft was further developed by committee members Nancy H. Allen (Colorado State University), Melanie A. Dodson (New York University), Donna P. Hitchings (University of Houston), Irene W. Hurlbert (University of California, San Diego), Geraldine L. Hutchins (AMIGOS), and Cynthia H. Roberts (Johns Hopkins University) into its current form. It is a testament to the good conceptual bones of this document that it has managed to effectively weather the dramatic shifts in online tides since its conception; it remains as serviceable a guide for planning instruction for CD-ROMs and online catalogs, as for other types of online line access-
Gary Handman, Chair, ACRL Bibliographic Instruction Section, Emerging Technologies in Instruction Committee

\section{Introduction}

We often fail to ask the right questions when planning end-user instruction. These lists of questions and criteria will help librarians find the best teaching methods for each situation, and will aid in planning successful educational programs.

The checklists are practical guides, each oriented around one of the commonly used teaching methods-classroom instruction, one-on-one instruction, and the newest method, computer assisted instruction. The lists will help with the selection of methodology by encouraging analysis of key factors such as time, staffing levels, equipment, and, of course, a variety of issues about end users themselves.

\section{Classroom instruction}

Workshops or presentations to classroom-size groups are commonly used by librarians to teach about the library and its resources. This approach has also been used to varying degrees of success for teaching the use of online catalogs. However, a survey (Rockman, LOEX Proceedings, 1987) of academic libraries offering end-user access to databases revealed that formal classroom instruction is not commonly used to teach searching skills. Even 
those libraries which do offer classroom instruction in searching often limit discussions, restricting coverage of searching techniques and processes. It is possible to combine classroom lecture, demonstration, and discussion with other instructional techniques. However, this section of the checklist encourages consideration of questions which apply when classroom instruction is the primary approach to teaching.

\section{Time}

A. Will the learner begin searching soon after instruction?

B. Will there be advanced sessions, and if so, how many workshops should be in the lesson series? low?

C. Will you offer repeat sessions if attendance is

D. How much preparation time on the part of librarians is needed to prepare materials and the lesson?

E. How much time will be required of the teaching faculty member (if this workshop is associated with a course)?

F. How much time will be spent by the student?

$\mathrm{G}$. Will the presentation result in increased or decreased time commitments for students, librarians, or faculty after the presentation?

H. How long should the classroom session be? Will the length vary by motivation of the faculty member arranging the session, or of the students signing up for a publicized workshop?

\section{Cost}

A. Does space for the classroom session involve cost?

B. Will there be enough equipment available for the group to do hands-on exercises? Is there appropriate equipment for high-quality demonstrations?

C. How will the library or the university fund practice searches if there are costs associated with access to the databases?

D. Do staffing levels allow more than one librarian to participate in each session?

E. Are there funds for continuing education programs both in database searching skills and in teaching skills?

F. Will there be an evaluation element provided which adds cost to the program, such as videotaping?

G. Are there other staff costs, such as student assistants or others helping grade exercises?

$H$. If the workshop is initiated by the library, are there costs associated with publicity?

\section{Knowledge Base}

A. What classroom experience do the librarians have? (Adequate teaching skills can be learned and improved through practice; excellence in teaching also requires talent.)
B. What level of searching expertise do the librarians have?

C. What content expertise do the librarians have in the subject areas involved?

D. What knowledge base about information structuresand organization of information exists in the students?

E. Will the workshop accommodate a variety of levels of student knowledge and skills?

F. If the instruction is linked to courses, will the teaching faculty be involved in workshop preparation? If so, what is the knowledge base in information organization of the faculty member?

\section{Instructional Design}

A. Will exercises follow the presentation?

B. Will students be able to ask questions during the presentation?

C. Will instructors be prepared with flexible back-up plans for equipment, space, supplies, or other difficulties?

D. How will the conceptual aspects of searching be conveyed? Will instructors address problemsolving elements of searching?

E. If the workshop is connected to a course, do other elements of the course involve problemsolving or critical thinking?

F. How will instructors teach controlled vocabulary?

\section{One-on-one instruction}

Librarians probably do most end-user instruction through individual contact, either at the reference desk, through term paper assistance, or at the time a user arrives for a CD-ROM use appointment. It is often difficult to spend adequate time with the user under these circumstances, and the learner probably lacks much conceptual background on the topic of information storage and retrieval. However, these questions might help librarians provide the most appropriate kind of assistance in each circumstance.

\section{Time}

A. If the student has asked for assistance, is it possible to give help at the time of the question?

$B$. If the librarian has initiated the encounter, is there time to provide the appropriate level of assistance?

C. Does the staffing plan provide people knowledgeable in searching at times when there are most likely to be questions?

D. Do instructional encounters involve materials, preparation, follow-up, or other programmatic ways to develop user skills? If so, is appropriate time planned?

E. Is time allocated by the library for staff development activities leading to good tutoring skills? 
F. Is time allocated by the library for one-on-one teaching program evaluation?

G. Can the student invest needed time in skills acquisition? If only minimal time is available, is the librarian prepared with materials enabling a successful short-term learning experience? If the student can invest time in an intensive learning experience, is the librarian prepared to schedule and provide such an experience?

\section{Cost}

A. Is equipment for instruction located near the reference service point?

B. Is equipment available at another staffed service point?

C. Is there an instructional laboratory for student searching skills development?

D. Does available equipment serve multiple, and possibly competing programs? Or is there dedicated equipment?

E. Is the library funded to support searches associated with reference questions? If so, will the library support searches done by patrons to answer their own inquiries?

F. Will the library support both equipment maintenance and staff skills maintenance?

G. Will vendor-supplied instructional materials be used?

H. Will in-house materials be developed for distribution?

I. Is there a cost involved with materials development, such as photocopying, computer time, etc.?

$\mathrm{J}$. Is there adequate staff to enable on-demand instruction to be focused and effective?

\section{Knowledge Base}

A. Are all reference staff (who might be asked to provide database searching skills) expert searchers?

B. Do those who might be asked to provide database searching skills have teaching skills?

C. How will the library encourage development of a variety of instructional approaches for one-onone teaching?

D. Is there an expert searcher/educator, or a team of experts, responsible for developing a broad skill base needed for extensive one-on-one instruction?

E. Are students motivated to increase knowledge and skills? What can the librarian do to improve motivation as well as skills for the individual?

F. Do students know when help is needed? Do they know where to get help? Are they encouraged to seek assistance?

G. Are students equipped with the level of independent learning and critical thinking to integrate new skills with previous learning patterns?

H. Are library staff able to respond to the variety of learning styles and needs of different users?

\section{Instructional Design}

A. Does the on-demand instructional package include attention to the conceptual foundations of searching?

$B$. Does the on-demand package address the needs of those who are less interested in the process of searching than the result? Can instructional design provide both the answer to an inquiry and information about end-user search skills?

C. Does the instructional design, including materials, maximize time when time limits exist?

D. How can the librarian and the library provide on-demand instruction which is conducive to the teaching of facts and details, problem- solving, and building conceptual foundations?

E. What links are provided to workshops, classroom, in-depth tutoring, or other more extensive instruction?

F. What methods can be used to provide selfhelp on demand?

G. Since one-on-one instruction involves interpersonal relationships, what can the librarian do to improve the level of personal attention and positive reinforcement, reducing the levels of intimidation?

\section{Computer-assisted instruction}

This is a fairly new approach to teaching end users to conduct computer searches. Many feel computer assisted instruction (CAI) reinforces some elements of computer use which assist in database searching. There are also a number of research efforts which have shown that CAI does as well or marginally better in accomplishing instructional objectives as traditional teaching methods. CAI also tends to improve the students' attitudes toward the content being taught.

To date, few fully developed CAI programs exist, the most noted being MEDLEARN developed by the National Library of Medicine. Other CAI software is primarily simulation to be used in conjunction with other teaching methods. With the increased availability of nonlinear hypertext design software, the number of libraries designing CAI to teach library use skills is increasing rapidly, and the logical link between using computers to leam and computers to retrieve information is encouraging libraries to use CAI for end-user education.

\section{Time}

A. With CAI programs, learners can proceed at their own pace, taking instruction as needed. Is software and hardware readily available? Are there other time limits on the use of computer equipment?

$B$. The user must take the initiative to begin instruction unless beginning the CAI lesson is part of a larger program. What is done to encourage the end user to approach the CAI software and begin? 
C. Is off-the-shelf or vendor-provided instructional software available and appropriate? If not, development of in-house software is a major investment of time on the part of the library.

D. Depending on software used, development can range up to 1,000 hours of training, design, testing, and evaluation by inexperienced librarians for each hour of instruction. It is recommended that a team of librarians receive basic training in instructional design. Can the library invest in this time? Is CAI development available in other campus offices? Are workshops in CAI software use available locally?

E. Can the development team include a member of the teaching faculty who is closely involved with the project?

F. Once developed and in use, with CAI, the burden of learning time is shifted to the student. Can end users take time to use the CAI? Is time planned for personal assistance during or after the CAI program?

\section{Cost}

\section{A. Equipment}

I. Is hardware and software available in sufficient quantity and in appropriate locations for both CAI development and student use?

2. Can end users have access to CAI programs at their own convenience?

3. Can end users use the same equipment for the CAI and online searching? Are there keyboard incompatibilities? If so, does the instruction note this? ment?

4. Are costs associated with space for equip-

\section{B. Staffing}

1. Are there costs associated with sending staff to CAI courseware training?

2. Will consultants be retained to assist with CAI design or implementation?

3. Once CAI is in place, will staff be allocated for in-person assistance with hardware use, screen interpretation, or counseling?

\section{Materials}

1. If CAI is microcomputer-based, are there multiple copies of the software? Are CAI lessons mounted on a fixed disk? Are terminals reserved for CAI use, or are floppy disks circulated for home use, or both?

2. If CAI is mainframe-based, is remote access possible, and has the library prepared instructions for access, dial-up, network access, passwords, accounts, and any other administrative necessity?

3. Does the CAI software involve concept testing and/or associated record-keeping for purposes of grades, reports, faculty liaison, or program evaluation? If so, are supply costs involved in processing the evaluation?

\section{Knowledge Base}

A. Do librarians designing the CAI have an understanding of principles of good interactive instructional design?

B. Do librarians designing CAI have experience in order to anticipate and assess user needs and instructional responses?

C. Do librarians designing CAI have the ability to organize the lessons? Good writing skills for this personal medium?

D. Are programming skills needed?

E. Are programmers or outside consultants engaged to teach librarians to be independent CAI designers, or to do the work?

F. Will librarians be responsible for maintaining the CAI software, keeping it up to date with organizational, service, or physical plant changes in the library?

G. Do librarians responsible for the development of CAI have necessary administrative skills for budget management and staff planning, as well as supplies, equipment, and space management?

$H$. If off-the-shelf CAI software is used, are other materials or skills needed to customize the educational program?

I. Do students have the necessary computer equipment skills to access the software? Reading skills to comprehend the instruction? Typing skills to respond to screen questions?

J. If end-user instruction is associated with a course, do faculty have an understanding of the nature of and time commitments for the CAI program?

K. Will faculty or others outside the library be expected to assist students in the content or application of the CAI program? How will the library provide faculty or others with skills necessary to answer student questions?

\section{Instructional Design}

A. Does the software allow users to set an independent learning pace?

B. Is the CAI available for consultation or review?

C. Is it easy to update?

D. Are screens designed to minimize text?

E. Are many responses and interactions required? Are there simulations of searches?

$F$. Can the student exit at any time?

G. Can the material be used for a wide variety of end users, or is it exclusively for a single program? Are instructional objectives clearly thought out and articulated?

H. Are accompanying printed or visual materials available and accessible?

I. Are complex procedures broken down into segments? Repeated for enforced learning? Are practice exercises accessible for complex procedures? 
J. Is the CAI used appropriately? It is easier to use CAI for teaching factual information about online systems, basic concepts, or procedures reinforced through simulation. It may be more difficult to use CAI to teach complex mental models about information structure, or a conceptual context surrounding search tasks. CAI may be better for teaching search strategy and problem-solving than printed materials because it is interactive. Have the members of the design team analyzed the instructional elements best suited to CAI methodology?

$\mathrm{K}$. Have end-user characteristics, time constraints, and motivation been considered in designing the CAI package? If it is necessary to spend a long time proceeding through CAI prior to trying a search, some end users may be discouraged from trying searching. Highly motivated, or highly independent end users may prefer CAI to asking for personal assistance.

\section{Printed materials}

The use of printed materials for instructional purposes is primary in many libraries. A survey of academic hibraries (Rockman, LOEX Proceedings, 1987) providing users online database access revealed that most offered clientele printed materials as the principal means of instruction, with reference librarians answering questions as they occurred. This section addresses considerations for the library using printed materials as its primary instructional approach.

\section{Time}

A. In-house development of printed materials can be time-consuming, and production time must also be planned for any materials to be designed and published. Is there a schedule for design, testing, evaluation and production of printed materials?

B. Is pretesting of printed materials part of the production schedule? If so, is there a group of actual users who can serve to pretest the materials?

C. Will the printed material be available when the system is being used or will it be available beforehand for study and later for reference?

D. Are frequent revisions planned? Is there a schedule for revision? Who will be responsible for the revisions? Will this responsibility be shared by more than one staff member?

E. Is the time faculty members spend a factor? If so, do teaching faculty prefer the use of printed products?

F. What time burden does the use of printed products place on the user? Will it take longer for the user to read a full explanation of a topic, understand and apply it, or to have a library staff member explain it verbally and provide a demonstration?

$\mathrm{G}$. What variables determine the amount of time to be spent by users depending on printed materials? Reading ability? Rereading efforts? Practice time? Are graphics used to break up text and illustrate the ideas and complex concepts?

$\mathrm{H}$. Will users want to take materials with them? What time factors are present in the off-site use of printed materials?

I. Libraries depending only on printed materials should expect many user questions. Has the increased staff time needed to answer these questions been considered when planning reference desk coverage?

\section{Cost}

A. Is there adequate funding to reproduce sufficient copies of all printed material? Are sufficient copies planned for all searching locations?

B. Is it cost effective to rely on vendor documentation?

C. Is the location of off-site searching equipment a factor in deciding to rely on print resources? If so, have mailing or delivery costs been figured into a budget for distribution of printed materials?

D. As noted above, libraries depending only on printed materials should expect many user questions. Is funding available for adequate staffing to provide answers?

E. Have funds been made available for furniture (tables, display racks) to distribute printed material? Space? Telephone use related to instruction?

\section{Knowledge Base}

A. Is local expertise on design/layout available?

B. Do those preparing printed material have expertise in writing and content organization?

C. Is a plan in place to evaluate printed material? Are staff available to evaluate vendor-provided material?

D. What are the characteristics of those intended to read and use printed materials? Do users have any searching skills already? Do users have adequate reading skills? Is layout and design appropriate for the level of users? (Highly organized and structured printed materials may be too complex for some users, while more experienced users might prefer material aimed at quickly providing specific assistance or information.)

E. Are users print-oriented learners? If not, can design features increase the interactive nature of the text?

F. Will users have patience and motivation to thoroughly read printed material? Can design compensate for user inclination not to read thoroughly?

\section{Instructional Design}

A. If printed materials are the sole instructional method, are they self-contained and fully explanatory? 
B. Have inherent characteristics of printed materials been considered in planning?

1. Can interactivity be a design feature, such as self-paced workbooks, questions with answers, tours, etc.?

2. Is the material written to present factual information about the search systems, procedural information about the program, system commands, definitions? If so, in what format? Handbook, dictionary, questions and answer?

3. What strategies will work best to convey conceptual information?

C. Have vendor-provided materials been compared to material to be designed in-house? Are vendor materials presenting enough conceptual information?

D. Have you considered what objectives should be met with printed materials?

1. Do you need tutorials?

2. Do you need system manuals?

3. Do you need quick reference guides?

\section{University of Michigan's M-Link expands with Superiorland Library Cooperative}

M-Link, the University of Michigan's electronic network connecting Michigan public libraries to the University Library, has announced the addition of the Superiorland Library Cooperative to the Network. The Cooperative serves 20 libraries in Michigan's Upper Peninsula and, with M-Link, is testing delivery of services through a public library cooperative structure.

M-Link is a pilot project funded by the W.K. Kellogg Foundation and the University of Michigan Library. Beginning November 1988, M-Link connected the University of Michigan Library to public libraries in seven Michigan communities: Battle Creek, Farmington, Grand Rapids, Hancock, Lapeer, Bay County, and Alpena. Headquartered in Ann Arbor, the M-Link staff has access to the University Library and faculty. M-Link manager Richard Hathaway reports that M-Link is now receiving 55 serious reference questions a month, and with the addition of the Superiorland Library Cooperative the number is steadily rising.

The function of the project is to demonstrate the ability of a multitype library network to share information, particularly with the aim of aiding economic and community development and to demonstrate statewide electronic networking of public libraries. M-Link emphasizes not only information sharing but the means to transmit it electronically. M-Link sponsors conferences concerning electronic networking, libraries and economic development, and libraries serving the needs of local govemments.

M-Link's primary goals are to assist local communities in their efforts to promote and plan economic development and to demonstrate how public libraries can be major players in this area. For example, members of economic development committees in Battle Creek needed information to help them manage the local impact of national socioeconomic problems. "They received information about programs across the nation for youth at risk and hard-to-serve adults," said Barbara Zichterman, M-Link coordinator at Battle Creek's Willard Library. At M-Link's suggestion, faculty in the University of Michigan's Urban Planning Program helped the Farmington City Council decide whether to grant or deny a zoning request. "They were able to make an informed decision about the addition of a mall that could have hurt business in an adjacent city," explained Beverly Papai, director of the Farmington Public Library.

Besides assisting communities with economic and community development, M-Link helps them build cultural and educational programs. In preparation for a visit from Russian students, M-Link helped Alpena librarians provide answers to questions about the Russian language. Through MLink, University of Michigan Library resources helped city planners prepare a grant proposal for the Michigan Council for the Humanities.

Participating libraries were selected through a competitive process. Microcomputers, modems, communications software (developed at the University of Michigan), telefax, and training were all provided to those libraries that needed it. M-Link services are provided free of charge. In return, the local libraries agree to promote the network to local businesses, govermment, schools, and community organizations. The member libraries' staffs send reference questions to Ann Arbor by electronic mail through the MichNet computer system, by phone, or fax. They can also dial-up and search the University of Michigan Library's online catalog.

For comments or questions contact: Richard Hathaway, University of Michigan Library, 209 Hatcher North, Ann Arbor, MI 48109-1205; (313) 763-9376. 